https://helda.helsinki.fi

\title{
Association study of MMP8 gene in osteoarthritis
}

\section{Nakki, Annu}

2016-01-02

Nakki , A, Rodriguez-Fontenla , C , Gonzalez , A, Harilainen , A , Leino-Arjas , P , Heliovaara , M , Eriksson, J G , Tallroth , K, Videman , T , Kaprio , J , Saarela , J \& Kujala , U M 2016 , ' Association study of MMP8 gene in osteoarthritis ' , Connective Tissue Research, vol. 57 , no. 1 , pp. 44-52 . https://doi.org/10.3109/03008207.2015.1099636

http://hdl.handle.net/10138/161019

https://doi.org/10.3109/03008207.2015.1099636

publishedVersion

Downloaded from Helda, University of Helsinki institutional repository.

This is an electronic reprint of the original article.

This reprint may differ from the original in pagination and typographic detail.

Please cite the original version. 


\section{Association study of MMP8 gene in osteoarthritis}

Annu Näkki, Cristina Rodriguez-Fontenla, Antonio Gonzalez, Arsi Harilainen, Päivi Leino-Arjas, Markku Heliövaara, Johan G. Eriksson, Kaj Tallroth, Tapio Videman, Jaakko Kaprio, Janna Saarela \& Urho M. Kujala

To cite this article: Annu Näkki, Cristina Rodriguez-Fontenla, Antonio Gonzalez, Arsi Harilainen, Päivi Leino-Arjas, Markku Heliövaara, Johan G. Eriksson, Kaj Tallroth, Tapio Videman, Jaakko Kaprio, Janna Saarela \& Urho M. Kujala (2016) Association study of MMP8 gene in osteoarthritis, Connective Tissue Research, 57:1, 44-52, DOI: 10.3109/03008207.2015.1099636

To link to this article: http://dx.doi.org/10.3109/03008207.2015.1099636

Accepted author version posted online: 17

Nov 2015.

Published online: 17 Nov 2015.

Submit your article to this journal $₫$

Џلll Article views: 104

Q View related articles $๘$

View Crossmark data $₫$ 


\title{
Association study of MMP8 gene in osteoarthritis
}

\author{
Annu Näkki (10) ${ }^{\mathrm{a}, \mathrm{b}, \mathrm{c}, \mathrm{d}}$, Cristina Rodriguez-Fontenlae, Antonio Gonzalez ${ }^{\mathrm{e}}$, Arsi Harilainenf, Päivi Leino-Arjas ${ }^{\mathrm{g}}$,

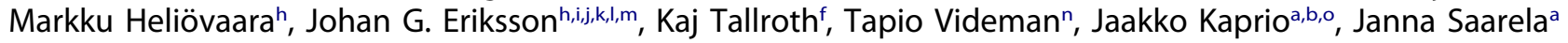 \\ and Urho M. Kujala ${ }^{\mathrm{p}}$
}

\begin{abstract}
anstitute for Molecular Medicine Finland FIMM, University of Helsinki, Helsinki, Finland; 'Department of Public Health, University of Helsinki, Helsinki, Finland; 'Department of Medical Genetics, University of Helsinki, Helsinki, Finland; dPublic Health Genomics Unit, National Institute for Health and Welfare, Helsinki, Finland; eLaboratorio Investigacion 10, Instituto de Investigacion Sanitaria- Hospital Clinico Universitario de Santiago, Santiago de Compostela, Spain; fORTON Orthopedic Hospital, Invalid Foundation, Helsinki, Finland; ${ }^{9}$ Department of Epidemiology

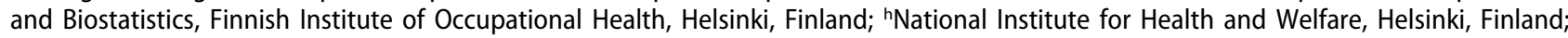
'Department of Chronic Disease Prevention, The National Institute for Health and Welfare, Helsinki, Finland; 'Department of General Practice and Primary Health Care, University of Helsinki, Helsinki, Finland; kUnit of General Practice, Helsinki University Central Hospital, Helsinki, Finland; 'Folkhälsan Research Center, Helsinki, Finland; ' ${ }^{2}$ asa Central Hospital, Vasa, Finland; "Faculty of Rehabilitation Medicine, University of Alberta, Edmonton, Canada; ${ }^{\circ}$ Department of Mental Health, National Institute for Health and Welfare, Helsinki, Finland; ${ }^{\mathrm{P} D e p a r t m e n t}$ of Health Sciences, University of Jyväskylä, Jyväskylä, Finland
\end{abstract}

\begin{abstract}
Objectives: Osteoarthritis (OA) is a joint disease common in the elderly. There is a prior functional evidence for different matrix metalloproteinases (MMPs), such as MMP8 and MMP9, having a role in the breakdown of cartilage extracellular matrix in OA. Thus, we analyzed whether the common genetic variants of MMP8 and MMP9 contribute to the risk of OA. Materials and methods: In total, 13 common tagging single-nucleotide polymorphisms (SNPs) were studied in a discovery knee OA cohort of 185 cases and 895 controls. For validation, two knee OA replication cohorts and two hand OA replication cohorts were studied (altogether 1369 OA cases, 4445 controls in the five cohorts). The $X^{2}$ test for individual study cohorts and Cochran-Mantel-Haenszel test for combined meta-analysis were calculated using Plink. Results: The rs1940475 SNP in MMP8 showed suggestive association in the discovery cohort ( $\mathrm{OR}=0.721,95 \% \mathrm{Cl} 0.575-0.906 ; p=0.005)$. Other knee and hand $\mathrm{OA}$ replication study cohorts showed similar trend for the predisposing allele without reaching statistical significance in independent replication cohorts nor in their meta-analysis $(p>$ $0.05)$. Meta-analysis of all five hand and knee OA study cohorts yielded a $p$-value of 0.027 (OR = $0.904,95 \% \mathrm{Cl} 0.826-0.989)$. Conclusions: Initial analysis of the MMP8 gene showed suggestive association between rs1940475 and knee OA, but the finding did not replicate in other study cohorts, even though the trend for predisposing allele was similar in all five cohorts. MMP-8 is a good biological candidate for OA, but our study did not find common variants with significant association in the gene.
\end{abstract}

ARTICLE HISTORY

Received 2 June 2015 Revised 16 September 2015 Accepted 18 September 2015

Published online 13 January 2016

\section{KEYWORDS}

Association; gene; matrix metalloproteinase 8; osteoarthritis

\section{Introduction}

The osteoarthritis (OA)-predisposing genes identified so far have been able to explain only little of the $39-65 \%$ heritability of this joint-destructing disease $(1,2)$. The disease affects the bone, cartilage, and synovium, inflammatory factors playing a role in the process. One characteristic feature of the cartilage degeneration in $\mathrm{OA}$ is the breakdown of extracellular matrix by different matrix metalloproteinases (MMPs) (3). Many studies have shown the role of MMPs in OA, MMP-1 and MMP-13 being some of the most relevant in OA $(4,5)$. Tetlow et al. (6) showed that the expression of different cartilage-breaking MMPs of chondrocytes was greater in the superficial zone of cartilage where degenerative changes were more common compared to the deeper zones.

The type I, II, and III collagen-breaking MMP-8 seems to play some role in $\mathrm{OA}$, even though it cannot be considered as the main factor in OA. The level of MMP-8 in the cartilage has shown to be higher in OA patients than in controls $(p=0.0135)$ (7) and the expression of MMP-8 is significantly increased in the joints of mice that have collagen-induced arthritis compared to healthy mice (8). Besides type II collagen, another component of the cartilage is the type IX collagen stabilizing the collagen network. MMP-9 can break down this collagen and other components in the cartilage and has been shown to be differentially

CONTACT Annu Näkki annu.nakki@thl.fi @ Institute for Molecular Medicine Finland FIMM, Room F315b, P.0. Box 20, University of Helsinki FI-00014,

Finland. Tel: +358-9-19125875. Fax: +358-20-610-8480.

(c) 2016 Taylor \& Francis 
expressed in OA compared to healthy cartilage. For example, MMP-9 was upregulated in human OA cartilage and synovium compared to controls (7). Similarly, Flannelly et al. (9) found the levels of MMP9 to be higher in the tibial articular chondrocytes of STR/ort mice that spontaneously generate OA than the control CBA mice, and MMP-9 was immunolocalized in growth cartilage. Also, Freemont et al. (10) have shown that the MMP9 gene is upregulated in deep cartilage layers of human knee OA samples in early disease stages.

Our aim was to investigate if there were common allelic variants in MMP8 and MMP9 genes that associate with knee OA. We hypothesized that the studied variants, or variants in high correlation with them, might have an impact on the structure or activity of the enzymes and thus affect their function by protecting or predisposing the carriers to OA.

\section{Study subjects}

The study was approved by the ethics committee of the Helsinki metropolitan hospital region in Finland $(11,12)$ and Ethical Committee for Clinical Research of Galicia in Spain. All individuals gave their written informed consent. We analyzed three knee OA study cohorts and two hand OA cohorts (Table 1).

\section{Finnish knee OA discovery cohort}

Our knee OA discovery cohort was composed of 185 knee OA cases of Finnish origin. Of these, 110 were

Table 1. Study cohorts.

\begin{tabular}{lcc}
\hline Study cohort & Cases & Controls \\
\hline Finnish knee OA discovery cohort & 185 & 895 \\
Radiological* & 110 & 0 \\
Clinical & 75 & 895 \\
Females (\%) & 72.4 & 53.6 \\
Finnish knee OA replication cohort & 302 & 1700 \\
Clinical & 302 & 1700 \\
Females (\%) & 66.2 & 64.6 \\
Spanish knee OA replication cohort & 254 & 449 \\
Total knee replacement surgery & 254 & 449 \\
Females (\%) & 80.3 & 35.4 \\
Knee OA in total & 741 & 3040 \\
Finnish hand OA replication cohort 1* & 132 & 435 \\
Radiological & 104 & 0 \\
Clinical** & 28 & 435 \\
Females (\%) & 81.8 & 36.3 \\
Finnish hand OA replication cohort 2 & 524 & 970 \\
Visual grading & 524 & 970 \\
Females (\%) & 67.7 & 49.5 \\
Hand OA in total & 656 & 1405 \\
All in total & 1369 & 4445 \\
\hline *Family-based study cohort in which & & \\
cohort includes also additional 21 unaffected family member. & ${ }^{* *}$ In total, \\
28 study subjects were included in the Finnish knee OA discovery cohort \\
(radiological) and Finnish hand OA replication cohort 1 (clinical). The \\
study subjects were included in the knee OA study group and excluded \\
from hand OA study group in the combined knee and hand OA meta- \\
analysis, and also excluded from the hand & OA study group in the \\
independent replication meta-analysis. & & \\
& & \\
& &
\end{tabular}

radiologically verified severe (at least grade $3 / 4$ in Kellgren and Lawrance classification), bilateral knee OA cases. Their symptoms were severe enough to fulfill the criteria for knee arthroplasty having pain and walking disability. The symptoms began at a mean age of 52 years (SD 12 years), and the mean age at first arthroplasty was 67 years (SD 8). Study subjects that suffered from RA or had previous severe knee trauma were excluded. Altogether, 28 of the knee OA patients also had physician-diagnosed hand OA. For details, see (11). The other half of the discovery cohort was selected from the population-based Finnish Health 2000 cohort $(n=8028)$. Genome-wide SNP array data were available for 2118 cohort members, who had been ascertained for a nested matched case-control study of metabolic syndrome (the Genmets study) (13). Seventyfive (75) of the 2118 individuals were over the age of 50 years and had a clinician-diagnosed probable or definite knee $\mathrm{OA}$ and were included in the discovery knee OA case group. In total, 895 Genmets study individuals were over 50 years of age and did not have clinician-diagnosed probable or definite knee or hip OA and were used as controls. Individuals suffering from RA or having an unknown RA status were excluded from the case and control groups $(n=28)$.

\section{Knee $O A$ replication cohorts}

For validation of the initial association, we analyzed one SNP in two independent knee OA replication cohorts. The first replication cohort consisted of 302 clinician-diagnosed knee OA cases and 1700 controls from the Health 2000 study that were not genotyped with the genome-wide SNP array. The cases were selected using the same clinician-diagnosed criteria as in the Finnish knee OA discovery cohort.

The second knee OA replication cohort consisted of 254 knee OA cases and 449 controls of Spanish ancestry. Cases were undergoing knee joint replacement and were included if a rheumatologist considered them to suffer from severe primary OA. Exclusion criteria were inflammatory, infectious, traumatic or congenital joint pathology, and lesions due to crystal deposition or osteonecrosis. Controls were recruited among subjects older than 55 years of age undergoing preoperative work-up for elective surgeries other than joint surgery and who did not show clinical manifestations of OA.

\section{Hand $O A$ replication cohorts}

For verification of the finding in another OA type, we used two Finnish hand OA study groups. The first hand 
OA replication cohort consisted of 132 Finnish radiologically verified severe (at least grade $3 / 4$ in Kellgren and Lawrance classification), bilateral familial hand OA patients and 21 unaffected family members. Eighty-four (84) of the cases were unrelated. Subjects with rheumatoid arthritis (RA) were excluded $(11,14)$. Of these, 28 individuals were also included in the Finnish knee OA discovery cohort. (The 28 study subjects were included in knee OA study group and excluded from hand OA study group in the combined hand and knee OA meta-analysis utilizing all five study cohorts. Also, the 28 study subjects were excluded from the independent replication meta-analysis with four replication cohorts.) The controls $(n=435)$ were selected from the Finnish twin cohort (males aged 35-70). One twin from a twin pair not having a clinician-diagnosed $\mathrm{OA}$ was included in the control group (11).

The second hand OA replication cohort was part of Finnish Helsinki Birth Cohort Study (15). All study subjects were over 56 years of age. Hand joints of the study subjects were visually evaluated and individuals with Heberden's nodes in at least one DIP joint were graded as affected $(n=524)$. Individuals graded as healthy $(n=970)$ had visually healthy and symptomless finger joints.

\section{Methods}

\section{Genotyping}

\section{Genotyping of the finnish knee OA discovery study cohort}

MMP8 and MMP9 genes were selected to a tag SNP association study based on their suggestive functional significance in OA and an initial candidate gene analysis of 25 genes (99 SNPs) (12) in a subset of the discovery knee OA study set (data not shown). Tag SNPs of the MMP8 and MMP9 genes also present in the genome-wide Illumina HumanHap 610 chip were selected (Illumina, Inc., San Diego, CA).

In total, 13 SNPs in MMP8 and MMP9 were genotyped in the entire Finnish knee OA discovery cohort using two methods. The Sequenom iPLEX Gold assay on the MassARRAY ${ }^{\circledast}$ Platform (Sequenom Inc., San Diego, CA) was used according to the manufacturer's instructions for genotyping of 110 cases. SNP assays were designed using the MassARRAY ${ }^{\mathrm{m}}$ Assay Design program (Sequenom Inc.) that designed PCR and extension primers and arranged the SNPs in two multiplexes. Each SNP multiplex was validated by genotyping 93 trio samples (i.e., 31 families with two parents and a child). The genotyping was done in 384-well plates with 35 duplicate samples and 8 non-template wells. The genotype data were assessed using the Sequenom Typer Analyzer program with quality control criteria of at least half of the assays in a sample well performing successfully, visually clear genotype clustering, at least $90 \%$ success rate for an assay, and $90 \%$ success rate for a sample. If the genotype calling, Mendelian inheritance test using the Pedcheck 1.1 program (16), duplicate samples, or non-template wells revealed unreliable SNP assay, the SNP was excluded from the study.

We also had data available for the selected SNPs from the Illumina HumanHap 610 whole-genome SNP chip (Illumina, Inc.) for 75 cases and 895 controls of the Genmets study (13) that were part of the Finnish knee OA discovery cohort. Markers with genotyping success rate of less than 95\%, minor allele frequency less than $1 \%$, and Hardy-Weinberg equilibrium less than $1 \times 10^{-6}$ were excluded. Of the 2440 individuals with the genome-wide data, we excluded those with genotyping success rate less than 95\%, high genomic heterozygosity indicating putative sample contamination, gender discrepancies, or close relatedness with another individual $\left(\pi^{\wedge}>0.1\right)(n=322)$. Altogether, 2118 individuals and 555,388 markers passed the quality control.

\section{Genotyping of the knee OA replication cohorts}

One SNP was genotyped in replication cohorts. The Finnish knee OA replication study cohort was genotyped using the Sequenom system (Sequenom Inc.) as described above.

Spanish knee OA replication study cohort was genotyped using single-base extension reactions with the SNaPshot Multiplex Kit (Applied Biosystems, Foster City, CA, USA). Genotypes were obtained in the AbiPrism 3130xl Genetic Analyzer (Applied Biosystems) with a $98.4 \%$ call rate.

\section{Genotyping of the hand $O A$ replication cohorts}

Finnish hand OA replication cohort 1 was genotyped using homogeneous MassEXTEND ${ }^{\mathrm{TM}}$ (hME) technology by the Sequenom MassARRAY ${ }^{\circledR}$ platform (Sequenom Inc.) as recommended by the manufacturer with additional quality control. Genotyping assays were designed using the SpectroDESIGNER 1.3 program (Sequenom Inc.) that designed PCR and extension primers and arranged the SNPs in to multiplexes of one to five SNPs. Each SNP multiplex was validated by genotyping 81 trio samples (i.e., 27 families with two parents and a child) to control for Mendelian incompatibilities using Pedcheck 1.1 program (16). The genotyping was done in 384-well plates with eight duplicate samples and 
eight non-template wells. If either automated or manual genotype calling using the Sequenom Typer Analyzer program (Sequenom Inc.), Mendelian inheritance test, duplicate samples, or non-template wells revealed unreliable SNP assay, the SNP was excluded from the study. Further, only SNPs with call rate of over $90 \%$ were included.

Finnish hand OA replication cohort 2 was genotyped using the Illumina HumanHap 610 chip (Illumina, Inc.) as described above.

\section{Data analyses}

First, the Haploview program (17) was used to measure the linkage disequilibrium (LD) structure of the studied genes in the discovery set controls as $r^{2}$ measure. Hardy-Weinberg equilibrium for each SNP was assessed using Haploview (17). The SNPSpd method was used to assess the $p$-value threshold for $5 \%$ significance, considering the LD structure of the studied SNPs. This method utilizes the LD structure of the studied region, and markers in strong LD are considered as one test (http://gump.qimr.edu.au/general/ daleN/SNPSpD/) $(18,19)$.

For unrelated individuals, the $\chi^{2}$ association analysis, meta-analysis (Cochran-Mantel-Haenszel), and heterogeneity between study cohorts in the meta-analysis ( $I^{2}$ heterogeneity index, Cochran Q) were calculated using the Plink program v1.07 (20) (http://pngu.mgh. harvard.edu/purcell/plink/). For the combined family and case-control setting of hand OA association analysis (Finnish hand OA replication cohort 1), the Pseudomarker program was used. The Pseudomarker program utilizes combined data of families and singletons and calculates the association with the presence of linkage $(21,22)$.

\section{Results}

Altogether, 13 SNPs were studied in the Finnish knee OA discovery study cohort. The SNPs covered $62 \%$ of the common variation in the MMP8 gene $( \pm 5 \mathrm{~kb})$ and $67 \%$ in the $M M P 9$ gene ( $\pm 5 \mathrm{~kb})$ according to the Tagger program (http://www.broadinstitute.org/mpg/ tagger/) (23). Maximum $r^{2}$ correlation of $80 \%$ between the markers and allele frequency threshold of $10 \%$ was used. Reference population was HapMap CEU: Utah residents with ancestry from northern and western Europe; phased HapMap Release 21 (24). The LD structures of the studied genes in discovery cohort controls are shown in Figure 1. Based on the SNPSpD method $(18,19)$ the level of $5 \%$ significance was reached with a $p$-value of 0.0057 corresponding to the effective number of nine SNPs. The most significant association was further analyzed in independent replication cohorts of knee $\mathrm{OA}$ and hand OA.

Two SNPs, rs1940475 and rs3765620, showed an association with knee $\mathrm{OA}$ in the Finnish knee OA discovery cohort $(p=0.005$ and $p=0.004$, respectively) (Table 2). The two SNPs were in LD with each other $\left(r^{2} 82 \%\right)$. Due to the high correlation between the SNPs, only the rs1940475 marker was further analyzed in two independent knee OA and in two independent hand OA replication cohorts. In all four study cohorts, the allele frequency difference between cases and controls was in the same direction as observed in the initial discovery study set of 185 cases and 895 controls. However, the initial finding did not replicate statistically significantly in any of the four independent replication study sets of knee and hand OA $(p>0.05)$ nor in a meta-analysis combing the four replication study sets $(p=0.236)$. When including the discovery study set in the meta-analysis,

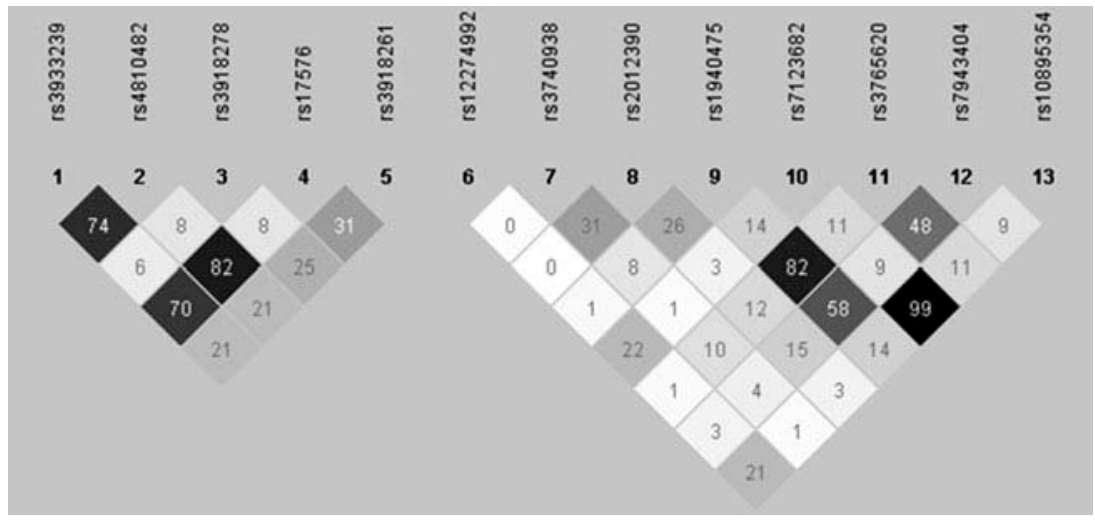

Figure 1. The LD structure of the studied genes in the controls. The LD structure of the MMP9 and MMP8 genes is presented as a measure of $r^{2}$. Stronger color indicates higher level of pairwise LD between each SNP pair, black color indicating $100 \%$ LD. 
Table 2. The results of association analysis in the Finnish knee OA discovery cohort.

\begin{tabular}{|c|c|c|c|c|c|c|c|c|c|c|}
\hline $\mathrm{Chr}$ & Gene & SNP & Location & Al. & Freq ctrls & Freq cases & $x^{2} p$-value & OR & L95 & U95 \\
\hline 20 & MMP9 & rs3933239 & 44062075 & A & 0.465 & 0.473 & 0.803 & 1.029 & 0.821 & 1.290 \\
\hline 20 & MMP9 & rs4810482 & 44067957 & $\mathrm{C}$ & 0.396 & 0.398 & 0.936 & 1.009 & 0.802 & 1.271 \\
\hline 20 & MMP9 & rs3918278 & 44069061 & A & 0.050 & 0.038 & 0.328 & 0.751 & 0.423 & 1.335 \\
\hline 20 & MMP9 & rs17576 & 44073632 & G & 0.390 & 0.392 & 0.945 & 1.008 & 0.799 & 1.272 \\
\hline 20 & MMP9 & rs3918261 & 44076999 & G & 0.169 & 0.175 & 0.792 & 1.041 & 0.772 & 1.403 \\
\hline 11 & MMP8 & rs12274992 & 102084124 & $\mathrm{~T}$ & 0.051 & 0.074 & 0.088 & 1.470 & 0.942 & 2.293 \\
\hline 11 & MMP8 & rs3740938 & 102092272 & A & 0.074 & 0.068 & 0.688 & 0.913 & 0.587 & 1.422 \\
\hline 11 & MMP8 & rs2012390 & 102095987 & $C$ & 0.205 & 0.186 & 0.417 & 0.888 & 0.666 & 1.183 \\
\hline 11 & MMP8 & $\mathrm{rs} 1940475^{\mathrm{a}}$ & 102098458 & $\mathrm{~T}$ & 0.493 & 0.413 & 0.005 & 0.721 & 0.575 & 0.906 \\
\hline 11 & MMP8 & rs7123682 & 102099237 & $C$ & 0.129 & 0.159 & 0.132 & 1.271 & 0.930 & 1.738 \\
\hline 11 & MMP8 & rs $3765620^{b}$ & 102100702 & $\mathrm{G}$ & 0.446 & 0.363 & 0.004 & 0.710 & 0.562 & 0.895 \\
\hline 11 & MMP8 & rs7943404 & 102103785 & G & 0.378 & 0.431 & 0.060 & 1.245 & 0.990 & 1.565 \\
\hline 11 & MMP8 & rs10895354 & 102104264 & $\mathrm{C}$ & 0.129 & 0.159 & 0.125 & 1.277 & 0.934 & 1.746 \\
\hline
\end{tabular}

$\mathrm{Chr}=$ chromosome; Location = genomic location in base pairs; Al. = minor allele for which the ORs are given; Freq ctrls = allele frequency in controls; Freq cases $=$ allele frequency in cases; $\mathrm{OR}=$ odds ratio; $\mathrm{L} 95$ and U95 $=95 \%$ confidence interval; ${ }^{\mathrm{a}}$ Genotyped also in other study cohorts (Table 3 ); ${ }^{\mathrm{b}} p$-value in the Finnish hand OA replication cohort $2=0.741$ based on the GWAS data; $\mathrm{OR}=0.975,95 \% \mathrm{Cl} 0.837-1.135$.

Table 3. Meta-analysis of rs1940475.

\begin{tabular}{lccccc}
\hline & Freq ctrls & Freq cases & $X^{2} p$-value & OR & L95 \\
\hline Finnish knee OA discovery cohort & 0.493 & 0.413 & 0.005 & 0.721 & 0.575 \\
Finnish knee OA replication cohort & 0.473 & 0.454 & 0.371 & 0.924 & 0.776 \\
Spanish knee OA replication cohort & 0.462 & 0.461 & 0.966 & 0.995 & 0.800 \\
Knee OA META & & & 0.039 & 0.884 & 0.789 \\
Finnish hand OA replication cohort 1 & 0.484 & 0.428 & $0.187^{\mathrm{a}}$ & 0.798 & 0.571 \\
Finnish hand OA replication cohort 2 & 0.474 & 0.465 & 0.639 & 0.965 & 0.994 \\
Hand OA META & & & 0.332 & 0.934 & 0.814 \\
Independent replication OA META & & & 0.236 & 0.943 & 1.121 \\
All cohorts OA META & & & 0.027 & 0.904 & 0.855 \\
\hline
\end{tabular}

${ }^{a}$ Only unrelated individuals, 84 cases and 435 controls, were included in the $x^{2}$ analysis. In the family-based association test with 132 affected, 21 unaffected and 435 controls, the $p$-value was 0.192 using Pseudomarker. The $p$-value for linkage was 0.0399 in the Pseudomarker analysis; ${ }^{b_{\text {including }}}$ the 28 clinical hand OA cases that are also part of the Finnish knee OA discovery cohort; ${ }^{C}$ excluding the 28 clinical hand OA cases that are also part of the Finnish knee OA discovery cohort.

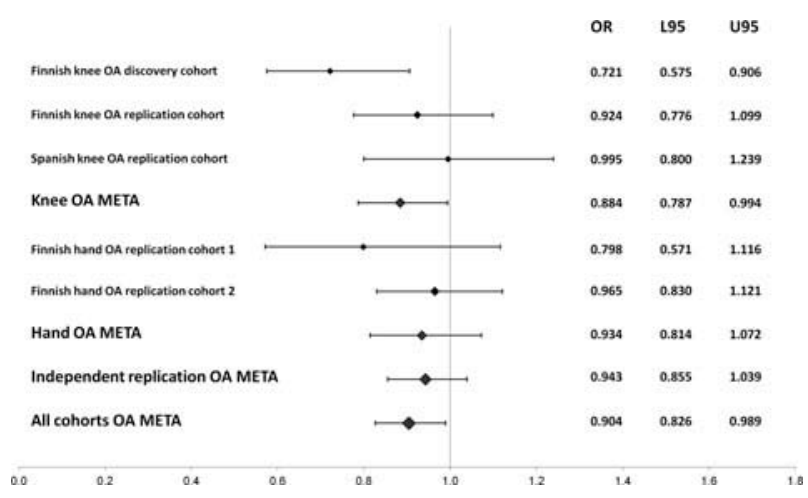

Figure 2. Forest plot of meta-analysis for the $\mathrm{T}$ allele of the 1940475 SNP. Odds ratios and 95\% confidence intervals. The sizes of the dots are in proportion with the amount of cases in the study cohort. Finnish hand OA replication cohort 1 includes the 28 clinical hand OA cases that are also part of the Finnish knee $\mathrm{OA}$ discovery cohort; independent replication meta-analysis excludes the 28 clinical hand OA cases that are also part of the Finnish knee OA discovery cohort.

p-value of 0.027 was obtained (Table 3; Figure 2). The $I^{2}$ heterogeneity index was $34.9(1-100)$ and the $p$-value for Cochran $Q$ statistic was 0.189 , indicating that there was no significant heterogeneity among the five study populations.

\section{Discussion}

Altogether, 13 SNPs in the MMP8 and MMP9 genes were studied in knee OA, and a statistically significant association with two SNPs (rs1940475 and rs3765620) in high LD with each other in MMP8 was observed ( $p<$ 0.0057). One of the SNPs rs1940475 was further analyzed in four independent replication cohorts, but the finding did not replicate in any of the knee and hand $\mathrm{OA}$ cohorts independently nor in a combined meta-analysis of the independent cohorts, although the trend for the $\mathrm{C}$-allele being more common in $\mathrm{OA}$ cases was similar in all five study cohorts.

The power to detect the level of association seen for rs 1940475 was $50 \%$ in the Finnish knee OA discovery cohort. Roughly 500 cases would have been needed for $80 \%$ power of detecting the association with $5 \%$ confidence level corresponding 95\% CI. When assuming similar allele frequencies for the follow-up cohorts as in the discovery cohort, the power to detect association in the individual follow-up cohorts varied between 30 and $80 \%$. The power was $99.9 \%$ in the meta-analysis of the four independent replication cohorts. However, the effect size in the Finnish knee OA discovery cohort has probably been overestimated (25). This is in accordance with previous publications showing that 
effect sizes typically seen in complex disease mapping require thousands of study samples for detection of association or for excluding the role of a single variant in a disease (26).

Both originally associated SNPs are non-synonymous. The rs1940475 changes the positively charged lysine to negatively charged glutamic acid (Lys87 to Glu) and the rs3765620 changes the polar threonine to nonpolar isoleucine (Thr32 to Ile). Both amino acid changes were predicted to be tolerated according to the SIFT program $(27,28)$.

We did not observe significant evidence of association to the studied common variants in the MMP8 gene. There is some functional evidence for the role of MMP-8 in OA, making it an interesting study target, even though it is not the main MMP released in OA. MMP-8 can cleave the major collagen of the cartilage, collagen type II, and also collagens type I, III, other ECM compounds, and non-structural molecules as well and affect neutrophil migration (29). MMP-8 is expressed by neutrophils (30), chondrocytes (31-33) especially mature chondrocytes (34), and chondrocytes following a proinflammatory stimulus (35). Billinghurst et al. (3) showed that the increased expression of MMP-8 is associated with increased cleavage of type II collagen in human osteoarthritic cartilage. The MMP- 8 mRNA has been shown to be absent from normal cartilage but present in naturally occurring $(7,36,37)$ and in IL- $1 \beta$-induced OA cartilage similarly to the MMP- 8 protein (6,7). MMP-8 mRNA levels were higher in chondrocytes obtained from the surrounding areas of OA lesion when compared with those seen in chondrocytes from other areas of the cartilage (38). Also the MMP-8 protein levels were higher in the superficial zone of OA cartilage and they were especially associated with areas suffering from matrix depletion, fibrillations, chondrocyte clusters, and loss of metachromasia. Protein levels were lower or absent from the deep zone and showed normal hyaline cartilage and chondrocyte morphology (6). Moreover, MMP-8 inhibition has shown promising results. Tetracycline (39), doxycycline (38), and Ro 32-3555 (an orally active collagenase selective inhibitor, Trocade $^{\otimes}$ ) (40) seem to inhibit neutrophil MMP-8 activity in vitro. Doxycycline has been tested successfully in reactive arthritis patients (41) and also Ro 32-3555 leads to significant protection of cartilage, inhibition of osteophyte formation, and reduction in joint space narrowing in the STR/Ort mouse model of OA (42).

Previous genome-wide association studies (GWASs) have revealed genome-wide significant $\left(p<5 \times 10^{-8}\right)$ findings in OA. Many of the findings are performed in large study samples, but as is typical in complex diseases, the effect sizes have been small and fine-mapping is required to identify the causal variants. The previous GWAS findings in OA include extracellular signaling molecule GDF5 (growth differentiation factor 5) (43,44), DVWA (von Willebrand factor) (45), 7q22 region with GPR22 (G-protein coupled receptor 22) $(46,47)$, a skeletal and pain-related gene $M C F 2 L$ (MCF.2 cell line derived transforming sequence-like, encoding the rho-specific guanine nucleotide exchange factor) (48), the FTO gene (fat mass and obesity associated) (48), membrane protein ASTN2 (astrotactin 2) (49), a wnt signaling gene DOT1L (DOT1-like, histone H3 methyltransferase) (50), nuclear receptor activator gene NCOA3 (nuclear receptor coactivator 3) (51), and HLA class II/III region (52).

The arcOGEN Consortium (49) published the details of their top 129 SNP findings $\left(p<10^{-5}\right)$ in OA with 7410 OA cases and 11009 controls, but the MMP8 and MMP9 genes were not among the published regions nor in the genome-wide significant regions of other GWASs mentioned above. However, the MMP9 gene is located in the chromosome 20q13.12 locus together with the NCOA3 gene associating with hip OA in the previous GWAS $\left(p=7.9 \times 10^{-9}, \mathrm{OR}=1.28,95 \% \mathrm{CI}\right.$ $1.18-1.39,11,277$ hip OA cases, 78,000 participants) (51), but the two genes are more than $1 \mathrm{Mb}$ apart, thus the negative finding of the current study is likely an independent signal from the association finding of the hip OA GWAS study in another study population.

\section{Conclusions}

A suggestive association in a discovery knee OA study cohort was observed with two common SNPs, rs1940475 and rs3765620, in the MMP8 gene, which has previously been shown to have a functional role in OA. However, the finding was not replicated with statistical significance in follow-up analyses of hand and knee OA.

\section{Acknowledgments}

We would like to warmly thank the study subjects for their participation in the present study. Minna Suvela is thanked for her technical expertise in the genotyping process. Michele C. Battié, Heidi Lönnberg, and Aki Salo are thanked for their contribution.

\section{Funding}

The financial supporters of the study are thanked for making the present study possible to conduct: TBDP National Doctoral Programme of Musculoskeletal Disorders and 
Biomaterials (formerly known as TBGS National Graduate School of Musculoskeletal Disorders and Biomaterials, and TULES Graduate School), Finnish Cultural Foundation, University of Helsinki foundation, Biomedicum Helsinki foundation, Otto A. Malm foundation, Emil Aaltonen Foundation. The Spanish study was supported by the Xunta de Galicia and by the Fondo de Investigacion Sanitaria of the Instituto de Salud Carlos III (Spain) grant 09/01431, which was partially funded by the European Union Fondo Europeo de Desarrollo Regional Program. The Finnish Twin Cohort has been supported by the Academy of Finland Centre of Excellence in Complex Disease Genetics (grants 213506 and 129680).

\section{Declaration of interest}

The authors report no conflicts of interest. The authors alone are responsible for the content and writing of the article.

\section{ORCID}

Annu Näkki (D) http://orcid.org/0000-0002-6436-0756

\section{References}

1. Spector TD, Cicuttini F, Baker J, Loughlin J, Hart D. Genetic influences on osteoarthritis in women: a twin study. BMJ 1996;312:940-3.

2. Neame RL, Muir K, Doherty S, Doherty M. Genetic risk of knee osteoarthritis: a sibling study. Ann Rheum Dis 2004;63:1022-7.

3. Billinghurst RC, Dahlberg L, Ionescu M, Reiner A, Bourne R, Rorabeck C, Mitchell P, Hambor J, Diekmann O, Tschesche H, Chen J, Van Wart H, Poole AR. Enhanced cleavage of type II collagen by collagenases in osteoarthritic articular cartilage. J Clin Invest 1997;99:1534-45.

4. Burrage PS, Mix KS, Brinckerhoff CE. Matrix metalloproteinases: role in arthritis. Front Biosci 2006;11:529-43.

5. Knauper V, Lopez-Otin C, Smith B, Knight G, Murphy G. Biochemical characterization of human collagenase-3. J Biol Chem 1996;271:1544-50.

6. Tetlow LC, Adlam DJ, Woolley DE. Matrix metalloproteinase and proinflammatory cytokine production by chondrocytes of human osteoarthritic cartilage: associations with degenerative changes. Arthritis Rheum 2001;44:585-94.

7. Davidson RK, Waters JG, Kevorkian L, Darrah C, Cooper A, Donell ST, Clark IM. Expression profiling of metalloproteinases and their inhibitors in synovium and cartilage. Arthritis Res Ther 2006;8:R124.

8. Booth G, Newham P, Barlow R, Raines S, Zheng B, Han S. Gene expression profiles at different stages of collagen-induced arthritis. Autoimmunity 2008;41:512-21.

9. Flannelly J, Chambers MG, Dudhia J, Hembry RM, Murphy G, Mason RM, Bayliss MT. Metalloproteinase and tissue inhibitor of metalloproteinase expression in the murine STR/ort model of osteoarthritis. Osteoarthritis Cartilage 2002;10:722-33.

10. Freemont AJ, Hampson V, Tilman R, Goupille P, Taiwo Y, Hoyland JA. Gene expression of matrix metalloproteinases 1,3 , and 9 by chondrocytes in osteoarthritic human knee articular cartilage is zone and grade specific. Ann Rheum Dis 1997;56:542-9.

11. Näkki A, Kouhia ST, Saarela J, Harilainen A, Tallroth K, Videman T, Battie MC, Kaprio J, Peltonen L, Kujala UM. Allelic variants of IL1R1 gene associate with severe hand osteoarthritis. BMC Med Genet 2010;11:50.

12. Videman T, Saarela J, Kaprio J, Nakki A, Levalahti E, Gill K, Peltonen L, Battie MC. Associations of 25 structural, degradative, and inflammatory candidate genes with lumbar disc desiccation, bulging, and height narrowing. Arthritis Rheum 2009;60:470-81.

13. Perttilä J, Merikanto K, Naukkarinen J, Surakka I, Martin NW, Tanhuanpaa K, Grimard V, Taskinen MR, Thiele C, Salomaa V, Jula A, Perola M, Virtanen I, Peltonen L, Olkkonen VM. OSBPL10, a novel candidate gene for high triglyceride trait in dyslipidemic Finnish subjects, regulates cellular lipid metabolism. J Mol Med 2009;87:825-35.

14. Leppävuori J, Kujala U, Kinnunen J, Kaprio J, Nissila M, Heliövaara M, Klinger N, Partanen J, Terwilliger JD, Peltonen L. Genome scan for predisposing loci for distal interphalangeal joint osteoarthritis: evidence for a locus on 2q. Am J Hum Genet 1999;65:1060-7.

15. Barker DJ, Osmond C, Forsen TJ, Kajantie E, Eriksson JG. Trajectories of growth among children who have coronary events as adults. $\mathrm{N}$ Engl J Med 2005;353:1802-9.

16. O'Connell JR, Weeks DE. PedCheck: a program for identification of genotype incompatibilities in linkage analysis. Am J Hum Genet 1998;63:259-66.

17. Barrett JC, Fry B, Maller J, Daly MJ. Haploview: analysis and visualization of LD and haplotype maps. Bioinformatics 2005;21:263-5.

18. Li J, Ji L. Adjusting multiple testing in multilocus analyses using the eigenvalues of a correlation matrix. Heredity 2005;95:221-7.

19. Nyholt DR. A simple correction for multiple testing for single-nucleotide polymorphisms in linkage disequilibrium with each other. Am J Hum Genet 2004;74:765-9.

20. Purcell S, Neale B, Todd-Brown K, Thomas L, Ferreira MA, Bender D, Maller J, Sklar P, de Bakker PI, Daly MJ, Sham PC. PLINK: a tool set for whole-genome association and population-based linkage analyses. Am J Hum Genet 2007;81:559-75.

21. Hiekkalinna T, Schaffer AA, Lambert B, Norrgrann P, Goring $\mathrm{HH}$, Terwilliger JD. PSEUDOMARKER: A Powerful Program for Joint Linkage and/or Linkage Disequilibrium Analysis on Mixtures of Singletons and Related Individuals. Hum Hered 2011;71:256-66.

22. Hiekkalinna $\mathrm{T}$, Goring $\mathrm{HH}$, Lambert B, Weiss $\mathrm{KM}$, Norrgrann P, Schaffer AA, Terwilliger JD. On the statistical properties of family-based association tests in datasets containing both pedigrees and unrelated case-control samples. Eur J Hum Genet 2011;20 (2):217-23. 
23. de Bakker PI, Yelensky R, Pe'er I, Gabriel SB, Daly MJ, Altshuler D. Efficiency and power in genetic association studies. Nat Genet 2005;37:1217-23.

24. International HapMap Consortium. The International HapMap Project. Nature 2003;426:789-96.

25. The Power Calculator. DSS Research, Washington, DC, USA; [cited 29 January 2013]. Available from: http:// www.dssresearch.com/KnowledgeCenter/toolkitcalcula tors/statisticalpowercalculators.aspx.

26. Wellcome Trust Case Control Consortium. Genomewide association study of 14,000 cases of seven common diseases and 3,000 shared controls. Nature 2007;447:661-78.

27. The Sift Program. J. Craig Venter Institute, San Diego CA, USA; [cited 10 March 2011]. Available from: http://sift.jcvi.org/.

28. Kumar P, Henikoff S, Ng PC. Predicting the effects of coding non-synonymous variants on protein function using the SIFT algorithm. Nat Protoc 2009;4:1073-81.

29. Lin M, Jackson P, Tester AM, Diaconu E, Overall CM, Blalock JE, Pearlman E. Matrix metalloproteinase-8 facilitates neutrophil migration through the corneal stromal matrix by collagen degradation and production of the chemotactic peptide Pro-Gly-Pro. Am J Pathol 2008;173:144-53.

30. Lazarus GS, Brown RS, Daniels JR, Fullmer HM. Human granulocyte collagenase. Science 1968;159:1483-5.

31. Chubinskaya S, Huch K, Mikecz K, Cs-Szabo G, Hasty KA, Kuettner KE, Cole AA. Chondrocyte matrix metalloproteinase-8: upregulation of neutrophil collagenase by interleukin-1 beta in human cartilage from knee and ankle joints. Lab Invest 1996;74:232-40.

32. Chubinskaya S, Huch K, Schulze M, Otten L, Aydelotte $\mathrm{MB}$, Cole AA. Gene expression by human articular chondrocytes cultured in alginate beads. J Histochem Cytochem 2001;49:1211-20.

33. Sasano Y, Zhu JX, Tsubota M, Takahashi I, Onodera K, Mizoguchi I, Kagayama M. Gene expression of MMP8 and MMP13 during embryonic development of bone and cartilage in the rat mandible and hind limb. J Histochem Cytochem 2002;50:325-32.

34. Bae JW, Takahashi I, Sasano Y, Onodera K, Mitani H, Kagayama M. Age-related changes in gene expression patterns of matrix metalloproteinases and their collagenous substrates in mandibular condylar cartilage in rats. J Anat 2003;203:235-41.

35. Barksby HE, Milner JM, Patterson AM, Peake NJ, Hui W, Robson T, Lakey R, Middleton J, Cawston TE, Richards CD, Rowan AD. Matrix metalloproteinase 10 promotion of collagenolysis via procollagenase activation: implications for cartilage degradation in arthritis. Arthritis Rheum 2006;54:3244-53.

36. Shlopov BV, Lie WR, Mainardi CL, Cole AA, Chubinskaya S, Hasty KA. Osteoarthritic lesions: involvement of three different collagenases. Arthritis Rheum 1997;40:2065-74.

37. Chubinskaya S, Kuettner KE, Cole AA. Expression of matrix metalloproteinases in normal and damaged articular cartilage from human knee and ankle joints. Lab Invest 1999;79:1669-77.
38. Shlopov BV, Smith GN, Jr., Cole AA, Hasty KA. Differential patterns of response to doxycycline and transforming growth factor beta1 in the down-regulation of collagenases in osteoarthritic and normal human chondrocytes. Arthritis Rheum 1999;42:719-27.

39. Suomalainen K, Sorsa T, Golub LM, Ramamurthy N, Lee HM, Uitto VJ, Saari H, Konttinen YT. Specificity of the anticollagenase action of tetracyclines: relevance to their anti-inflammatory potential. Antimicrob Agents Chemother 1992;36:227-9.

40. Lewis EJ, Bishop J, Bottomley KM, Bradshaw D, Brewster M, Broadhurst MJ, Brown PA, Budd JM, Elliott L, Greenham AK, Johnson WH, Nixon JS, Rose F, Sutton B, Wilson K. Ro 32-3555, an orally active collagenase inhibitor, prevents cartilage breakdown in vitro and in vivo. $\mathrm{Br} \mathrm{J}$ Pharmacol 1997;121:540-6.

41. Lauhio A, Salo T, Ding Y, Konttinen YT, Nordstrom D, Tschesche H, Lahdevirta J, Golub LM, Sorsa T. In vivo inhibition of human neutrophil collagenase (MMP-8) activity during long-term combination therapy of doxycycline and non-steroidal anti-inflammatory drugs (NSAID) in acute reactive arthritis. Clin Exp Immunol 1994;98:21-8.

42. Brewster M, Lewis EJ, Wilson KL, Greenham AK, Bottomley KM. Ro 32-3555, an orally active collagenase selective inhibitor, prevents structural damage in the STR/ORT mouse model of osteoarthritis. Arthritis Rheum 1998;41:1639-44.

43. Miyamoto $\mathrm{Y}$, Mabuchi A, Shi D, Kubo T, Takatori $\mathrm{Y}$, Saito S, Fujioka M, Sudo A, Uchida A, Yamamoto S, Ozaki K, Takigawa M, Tanaka T, Nakamura Y, Jiang Q, Ikegawa S. A functional polymorphism in the 5' UTR of GDF5 is associated with susceptibility to osteoarthritis. Nat Genet 2007;39:529-33.

44. Valdes AM, Evangelou E, Kerkhof HJ, Tamm A, Doherty SA, Kisand K, Kerna I, Uitterlinden A, Hofman A, Rivadeneira F, Cooper C, Dennison EM, Zhang W, Muir KR, Ioannidis JP, Wheeler M, Maciewicz RA, van Meurs JB, Arden NK, Spector TD, Doherty M. The GDF5 rs143383 polymorphism is associated with osteoarthritis of the knee with genome-wide statistical significance. Ann Rheum Dis 2011;70:873-5.

45. Miyamoto Y, Shi D, Nakajima M, Ozaki K, Sudo A, Kotani A, Uchida A, Tanaka T, Fukui N, Tsunoda T, Takahashi A, Nakamura Y, Jiang Q, Ikegawa S. Common variants in DVWA on chromosome 3p24.3 are associated with susceptibility to knee osteoarthritis. Nat Genet 2008;40:994-8.

46. Evangelou E, Valdes AM, Kerkhof HJ, Styrkarsdottir U, Zhu Y, Meulenbelt I, Lories RJ, Karassa FB, Tylzanowski P, Bos SD, Akune T, Arden NK, Carr A, Chapman K, Cupples LA, Dai J, Deloukas P, Doherty M, Doherty S, Engstrom G, Gonzalez A, Halldorsson BV, Hammond CL, Hart DJ, Helgadottir H, Hofman A, Ikegawa S, Ingvarsson $\mathrm{T}$, Jiang Q, Jonsson $\mathrm{H}$, Kaprio J, Kawaguchi H, Kisand K, Kloppenburg M, Kujala UM, Lohmander LS, Loughlin J, Luyten FP, Mabuchi A, McCaskie A, Nakajima M, Nilsson PM, Nishida N, Ollier WE, Panoutsopoulou K, van de Putte $T$, Ralston $\mathrm{SH}$, Rivadeneira F, Saarela J, Schulte-Merker S, Shi D, Slagboom PE, Sudo A, Tamm A, Thorleifsson G, 
Thorsteinsdottir U, Tsezou A, Wallis GA, Wilkinson JM, Yoshimura N, Zeggini E, Zhai G, Zhang F, Jonsdottir I, Uitterlinden AG, Felson DT, van Meurs JB, Stefansson K, Ioannidis JP, Spector TD. Meta-analysis of genome-wide association studies confirms a susceptibility locus for knee osteoarthritis on chromosome 7q22. Ann Rheum Dis 2010;70:349-55.

47. Kerkhof HJ, Lories RJ, Meulenbelt I, Jonsdottir I, Valdes AM, Arp P, Ingvarsson T, Jhamai M, Jonsson H, Stolk L, Thorleifsson G, Zhai G, Zhang F, Zhu Y, van der Breggen R, Carr A, Doherty M, Doherty S, Felson DT, Gonzalez A, Halldorsson BV, Hart DJ, Hauksson VB, Hofman A, Ioannidis JP, Kloppenburg M, Lane NE, Loughlin J, Luyten FP, Nevitt MC, Parimi N, Pols HA, Rivadeneira F, Slagboom EP, Styrkarsdottir U, Tsezou A, van de Putte T, Zmuda J, Spector TD, Stefansson K, Uitterlinden AG, van Meurs JB. A genome-wide association study identifies an osteoarthritis susceptibility locus on chromosome 7q22. Arthritis Rheum 2011;62:499-510.

48. Day-Williams AG, Southam L, Panoutsopoulou K, Rayner NW, Esko T, Estrada K, Helgadottir HT, Hofman A, Ingvarsson T, Jonsson $\mathrm{H}$, Keis A, Kerkhof HJ, Thorleifsson G, Arden NK, Carr A, Chapman K, Deloukas P, Loughlin J, McCaskie A, Ollier WE, Ralston SH, Spector TD, Wallis GA, Wilkinson JM, Aslam N, Birell F, Carluke I, Joseph J, Rai A, Reed M, Walker K, Doherty SA, Jonsdottir I, Maciewicz RA, Muir KR, Metspalu A, Rivadeneira F, Stefansson K, Styrkarsdottir U, Uitterlinden AG, van Meurs JB, Zhang W, Valdes AM, Doherty M, Zeggini E. A variant in MCF2L is associated with osteoarthritis. Am J Hum Genet 2011;89:446-50.

49. Zeggini E, Panoutsopoulou K, Southam L, Rayner NW, Day-Williams AG, Lopes MC, Boraska V, Esko T, Evangelou E, Hoffman A, Houwing-Duistermaat JJ, Ingvarsson $\mathrm{T}$, Jonsdottir I, Jonnson $\mathrm{H}$, Kerkhof $\mathrm{HJ}$, Kloppenburg M, Bos SD, Mangino M, Metrustry S, Slagboom PE, Thorleifsson G, Raine EV, Ratnayake M, Ricketts M, Beazley C, Blackburn H, Bumpstead S, Elliott KS, Hunt SE, Potter SC, Shin SY, Yadav VK, Zhai G, Sherburn K, Dixon K, Arden E, Aslam N, Battley PK, Carluke I, Doherty S, Gordon A, Joseph J, Keen R, Koller NC, Mitchell S, O’Neill F, Paling E, Reed MR, Rivadeneira F, Swift D, Walker K, Watkins
B, Wheeler M, Birrell F, Ioannidis JP, Meulenbelt I, Metspalu A, Rai A, Salter D, Stefansson K, Stykarsdottir U, Uitterlinden AG, van Meurs JB, Chapman K, Deloukas P, Ollier WE, Wallis GA, Arden N, Carr A, Doherty M, McCaskie A, Willkinson JM, Ralston SH, Valdes AM, Spector TD, Loughlin J. Identification of new susceptibility loci for osteoarthritis (arcOGEN): a genome-wide association study. Lancet 2012;380:815-23.

50. Evangelou E, Valdes AM, Castano-Betancourt MC, Doherty M, Doherty S, Esko T, Ingvarsson T, Ioannidis JP, Kloppenburg M, Metspalu A, Ntzani EE, Panoutsopoulou K, Slagboom PE, Southam L, Spector TD, Styrkarsdottir U, Stefanson K, Uitterlinden AG, Wheeler M, Zeggini E, Meulenbelt I, van Meurs JB. The DOT1L rs12982744 polymorphism is associated with osteoarthritis of the hip with genome-wide statistical significance in males. Ann Rheum Dis 2013;72:1264-5.

51. Evangelou E, Kerkhof HJ, Styrkarsdottir U, Ntzani EE, Bos SD, Esko T, Evans DS, Metrustry S, Panoutsopoulou K, Ramos YF, Thorleifsson G, Tsilidis KK, Arden N, Aslam N, Bellamy N, Birrell F, Blanco FJ, Carr A, Chapman K, Day-Williams AG, Deloukas P, Doherty M, Engstrom G, Helgadottir HT, Hofman A, Ingvarsson T, Jonsson H, Keis A, Keurentjes JC, Kloppenburg M, Lind PA, McCaskie A, Martin NG, Milani L, Montgomery GW, Nelissen RG, Nevitt MC, Nilsson PM, Ollier WE, Parimi N, Rai A, Ralston SH, Reed MR, Riancho JA, Rivadeneira F, Rodriguez-Fontenla C, Southam L, Thorsteinsdottir U, Tsezou A, Wallis GA, Wilkinson JM, Gonzalez A, Lane NE, Lohmander LS, Loughlin J, Metspalu A, Uitterlinden AG, Jonsdottir I, Stefansson K, Slagboom PE, Zeggini E, Meulenbelt I, Ioannidis JP, Spector TD, van Meurs JB, Valdes AM. A meta-analysis of genome-wide association studies identifies novel variants associated with osteoarthritis of the hip. Ann Rheum Dis 2013;73:2130-6.

52. Nakajima M, Takahashi A, Kou I, Rodriguez-Fontenla C, Gomez-Reino JJ, Furuichi T, Dai J, Sudo A, Uchida A, Fukui N, Kubo M, Kamatani N, Tsunoda T, Malizos KN, Tsezou A, Gonzalez A, Nakamura Y, Ikegawa S. New sequence variants in HLA class II/III region associated with susceptibility to knee osteoarthritis identified by genome-wide association study. PLoS One 2010;5(3):e9723. 